\title{
CHANGES IN THE STRUCTURE OF URBAN MOBILITY WITH THE DEVELOPMENT OF INFRASTRUCTURE FOR PUBLIC TRANSPORT AND CYCLISTS IN CITIES
}

\author{
DMITRII ZAKHAROV \& ALEXEY FADYUSHIN \\ Department of Road Transport Operation, Industrial University of Tyumen, Russia
}

\begin{abstract}
This paper deals with the transport supply influence on the functioning parameters on the large city urban mobility structure that does not have off-street transport. The influence of the paid parking cost, the bus lane length and bike lanes. The influence of the cost of paid parking, the length of bus lanes and bike lanes on the share of travel by personal and public transport, cycling and pedestrian travel has been established. An assessment of the change in the passenger traffic of individual stopping points and passenger traffic on public transport routes was carried out with a change in the structure of urban mobility. The structure of urban mobility was determined using simulation modelling with a macroscopic transport model of a large city with a population of over 800,000 people. The parameters of three-factor mathematical models are determined, the adequacy of the models is checked and the static characteristics are presented.
\end{abstract}

Keywords: transport planning and modelling, urban transport system, paid parking, bike lanes, bus lane, pedestrian traffic, urban mobility.

\section{INTRODUCTION}

One of the drivers of economic development of countries is the development of cities and the number of inhabitants in them. Cities in emerging economies are experiencing difficulties in developing transport systems. With an increase in the number of residents, large cities receive not only competitive advantages in the economy, but also problems in ensuring sustainable mobility of citizens [1]-[9] and air pollution with exhaust gases from cars [10], [11].

The trend of the last decade in the development of urban transport systems is the implementation of a set of measures within the framework of the "mobility as a service" (MaaS) concept [12], [13]. The world experience in the development of sustainable urban mobility is to create priority conditions for public transport and cyclists in comparison with the use of a private car [14]-[16] and the formation of demand for travel by public transport by a complex of socio-economic and political measures. To reduce the number of trips by private vehicles in many cities of the world and the Russian Federation, the number of parking lots is reduced and a payment for parking of personal vehicles is introduced [17]-[20].

The structure of transport demand by means of transport and transportation methods is the result of the choice of people when making a decision to move around the city [21]-[23]. To study the reasons and conditions influencing the choice, it is necessary to establish a model of transport behavior. Research in this area has found wide application in many countries and cities [24], [25].

The transport behavior model both influences and depends on the urban transport system. System operation parameters (average vehicle speed, correspondence time, ride comfort and safety) affect the choice of the city residents' method of travel. When a resident of the city changes the way of movement, the parameters of the functioning of the transport system change. 
The structure of urban mobility depends on the weather, climatic, transport and road conditions of vehicle operation and socio-demographic, geographical and economic factors. The structure of urban mobility in different cities of the world differs significantly [26]. The level of development of the transport infrastructure has a significant impact on the distribution of demand by means of transport and methods of transportation [27], [28]. Each city has its own optimal structure of transport mobility, at which the balance and stability of the transport system are achieved. With an imbalance in transport demand and supply, the time for correspondence increases, and the quality of transport services for the population of cities decreases [29].

The spread of Coronavirus Covid-19 in 2020 has had a significant impact on urban transport systems. During the period when restrictions on the movement and operation of enterprises were introduced, the transport system was subjected to significant impacts [30], [31].

The aim of the work is to establish the influence of the development of infrastructure for public transport, cycling and parking space on the structure of urban mobility in cities.

\section{MATERIALS AND METHODS}

The article discusses activities that affect sustainable urban mobility: paid parking, bike lanes, pedestrian infrastructure, urban ground public transport. In this work, transport planning and modelling were used to study the properties of the urban transport system.

The creation of the transport model was carried out in 2018-2019 with subsequent updating. The studies presented in this paper do not take into account the impact of the Coronavirus Covid-19 pandemic on urban mobility and the parameters of the functioning of the urban transport system.

We evaluated the following parameters of the functioning of the urban transport system in the morning:

- $\quad$ share of movements by means of transport and on foot (structure of urban mobility);

- passenger exchange of public transport stopping points;

- passenger traffic on selected public transport routes.

We assessed the influence of several factors on the change in the parameters of the functioning of the urban transport system:

- the cost of paid parking in the central part of the city;

- the length of bus lanes on city roads;

- the length of bike lanes in the city's road network.

Changing the parameters of the functioning of the urban transport system occurs due to several processes and is a multi-factor process. Paid parking creates prerequisites for not using personal vehicles. New bus lanes increase the speed of communication by land transport, and, consequently, make public transport more competitive and comfortable. Bike lanes increase the connectivity for cyclists and the demand for this mode of travel. The combined impact of limiting demand for private car travel and encouraging other modes of travel and walking is shaping sustainable urban mobility.

Transport modelling was carried out in the PTV Visum program. The macroscopic transport model of the city with a population of 800,000 people includes 400 transport regions, 7,750 nodes, 17,300 sections. The total length of the city's road network is 2,424 $\mathrm{km}$, including $1,200 \mathrm{~km}$ of highways, the number of traffic lights $=381$ units, the total number of movements by private cars $=48,131$ units. 
Transport modelling makes it possible to evaluate the change in the parameters of the urban transport system when the external and internal conditions affecting the system change. By creating lanes for public transport and bike lanes in the transport model of the city, the resistance on the sections (sections of highways) for these transport systems is reduced. The main parameter of resistance in work is the time spent on movement. Therefore, the model reduces travel times on public transport and bicycle. As the charge for parking in the city center increases, the resistance for personal vehicles increases in the model. To do this, the parking fee is converted into time costs, taking into account the economic indicators for the city (the level of income of the population and the cost of paid parking).

Correspondences between transport areas by demand segments are allocated to different modes of transport (modes) using a cost matrix [32]. The paper considers the morning time, when the main transport demand falls on the segments "home - work" and "home - study". With a significant change in resistance of the transport systems, the transport demand is redistributed to other systems.

Weather and climatic (air temperature, precipitation, etc.), transport and road conditions affect the comfort of travel, and, therefore, affect the structure of urban mobility. The simulation was carried out for optimal weather, climatic and road conditions with basic (standard) program settings for the city of Tyumen (Russia).

\section{RESULTS}

According to experts' forecasts, the number of residents in Tyumen will increase to 1.2 million by 2040 . The increase in 19 years can reach 460,000 people. At the current level of motorization, 230,000 cars will appear in the city. The increase in the area of the city will increase the average travel distance and time. This will lead to a deterioration of the situation on highways: an increase in traffic congestion and the amount of emission of harmful substances with exhaust gases from cars, and an increase in road accidents.

To preserve the quality of transport services for residents of the city of Tyumen, the Program for the Integrated Development of Transport Infrastructure plans to build more than 60 road transport infrastructure facilities. The main role in ensuring sustainable mobility of the Tyumen population is assigned to public transport, the share of which will increase from $31 \%$ to $44 \%$ (Fig. 1). At the same time, the share of pedestrian movements decreases from $16 \%$ to $14 \%$.

The structure of urban mobility (2040)

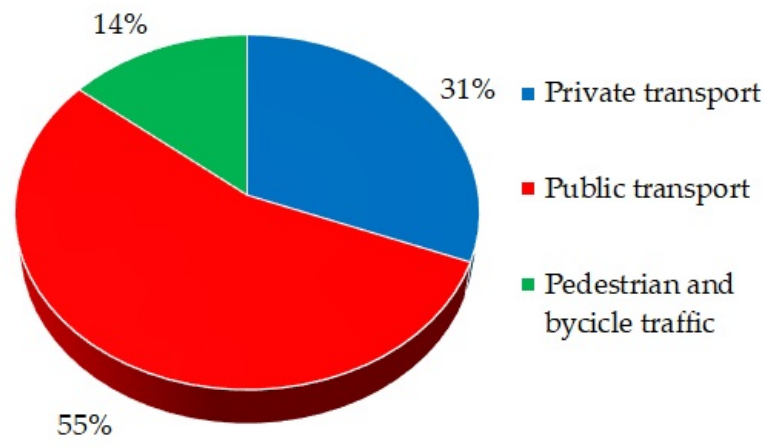

Figure 1: The structure of mobility of the population of Tyumen according to the Program for the Integrated Development of Transport Infrastructure forecast for 2040. 
This requires a scientific and methodological substantiation of changes in the structure of urban mobility under the influence the most important of factors. With a lack of financial resources and non-fulfilment of plans for the construction of infrastructure facilities, the road situation and the quality of passenger traffic may deteriorate. A further increase in the number of personal cars cannot be ruled out due to the desire of people to protect themselves from viral infections when traveling. This proves the relevance of studies to determine a balanced structure of urban mobility to ensure sustainable urban mobility.

The structure of urban mobility can be divided into four travelling modes, which are considered in macroscopic transport models: individual transport, public transport, bicycles and walking. The share of each travelling mode in the structure of urban mobility for a city with constant values of income of residents, cost of automobile fuel, state of the economy, demographic situation and structure of settlement is determined by a mathematical additive model based on the main effects and depends on three factors:

$$
\begin{gathered}
\Delta_{\text {car }}=\Delta_{\text {car } .0}+S_{1}\left(\mathrm{C}_{p p}-\mathrm{C}_{p p 0}\right)^{2}-S_{2} L_{\text {buslane }}-S_{3} L_{\text {bikelane }} \\
\Delta_{p t}=\Delta_{p t .0}-S_{1}\left(\mathrm{C}_{p p}-\mathrm{C}_{p p 0}\right)^{2}+S_{2} L_{\text {buslane }}-S_{3} L_{\text {bikelane }} \\
\Delta_{\text {ped }}=\Delta_{\text {ped.0 }}+S_{1}\left(\mathrm{C}_{p p}-\mathrm{C}_{p p 0}\right)^{2}-S_{2} L_{\text {buslane }}-S_{3} L_{\text {bikelane }} \\
\Delta_{\text {bike }}=\Delta_{\text {bike } .0}-S_{1}\left(\mathrm{C}_{p p}-\mathrm{C}_{p p 0}\right)^{2}-S_{2} L_{\text {buslane }}+S_{3} L_{\text {bikelane }} \\
\Delta_{c a r}+\Delta_{p t}+\Delta_{p e d}+\Delta_{\text {bike }}=100 \%
\end{gathered}
$$

where $\Delta_{\text {car. } 0}=$ private car share under actual conditions; $\Delta_{\text {pt. }}=$ public transport share under actual conditions; $\Delta_{\text {ped. } .}=$ share of walking under actual conditions; $\Delta_{b i k e .0}=$ cycling share under actual conditions; $C_{p p}=$ private car parking cost, rubles per hour; $L_{\text {buslane }}=$ bus-only lanes length, $\mathrm{km} ; L_{\text {bikelane }}=$ bike lane length, $\mathrm{km} ; S_{\mathrm{j}}=$ parameter of sensitivity to changes in the $\mathrm{j}$-th factor.

The shares ratio of movements by transport type and travelling modes affects the average time for the implementation of travels.

\subsection{The influence of the cost of parking private cars on the structure of urban mobility}

All major cities in the world have gone through the problem of lack of parking spaces for private cars in the central areas. To reduce the number of trips to the city center by private transport, the introduction of parking fees for private cars is widely used.

The hypothesis of the study is that with an increase in the cost of paid parking in the city center, there is an increase in the share of trips by public transport, taxis, carsharing cars, cycling and a decrease in the share of private cars.

Transport modelling makes it possible to assess the change in the parameters of the urban transport system when the external and internal conditions affecting the system change. The introduction of payment for parking personal vehicles in the street and road network in the central part of the city leads to a change in the structure of mobility of the population in the city as a whole, and especially when moving to the city center (Fig. 2).

With the introduction of paid parking and a tariff of 40 rubles per hour, there is an increase in the share of trips to the city center by public transport by $2.9 \%$ and a decrease by personal transport by $3.63 \%$. The share of pedestrian traffic increased by $0.8 \%$. With the increase in the cost of one hour of parking, changes in parameters increase. As the cost of paid parking increases, the share of cycling movements changes insignificantly due to the short length of bike lanes, the lack of bike rentals, and the lack of bike parking. 


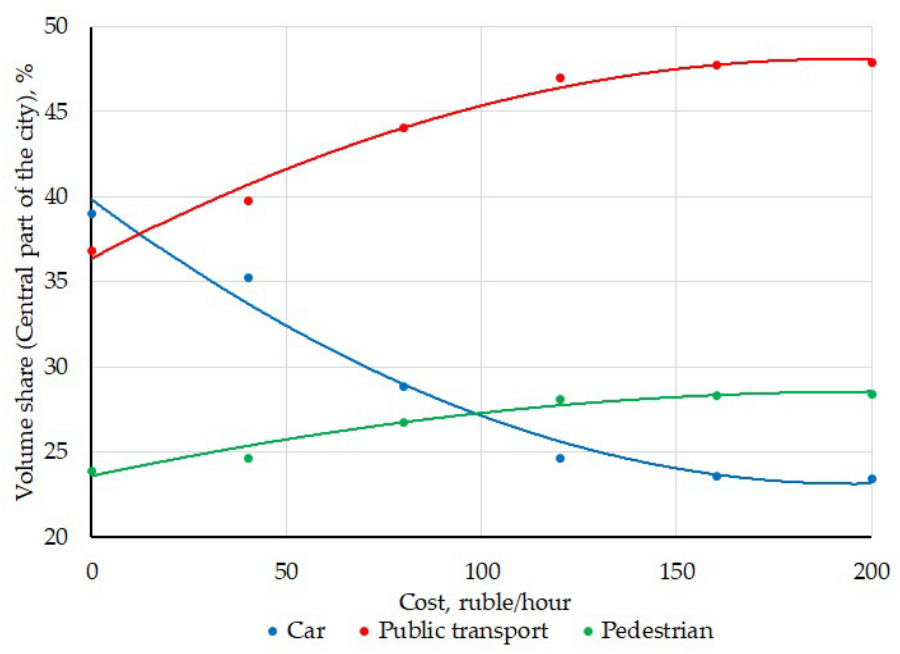

Figure 2: The impact of parking costs on the share of transfers to the paid parking area (central part of the city).

The nonlinear view of the dependence in Fig. 2 depends on the ratio of people's income and travel expenses on personal transport. With a low cost of parking a personal car, the car owner will not refuse to use it. When the cost rises, when parking costs represent a significant share of the car owner's income, there will be an increase in refusals to travel to the paid parking area for full-day work purposes.

With a further increase in the parking cost, the decrease in the share of trips by personal transport will be less intense. At the same time, there will not be a complete rejection of travel, since for a group of people with a large income, the cost of parking a car will not be critical. Also, travel to the city center by taxi and car sharing cars continues.

The greatest changes in the structure of urban mobility occur when the cost of 1 hour of parking rises to 120 rubles. A further increase in the cost of parking has a less intense change. With the additional demand for trips by public transport, the number of passengers transported on certain routes (Table 1). The biggest changes are taking place on routes passing through the zone of paid parking and stopping points in the city center.

Table 1: Changes in passenger traffic on certain routes with the introduction of paid parking (120 rubles per hour) in the central part of the city.

\begin{tabular}{|c|l|c|c|c|}
\hline $\begin{array}{c}\text { Route } \\
\text { No. }\end{array}$ & \multirow{2}{*}{ Traffic direction } & \multicolumn{2}{|c|}{ Passenger traffic on the route, pers. } & \multirow{2}{*}{$\begin{array}{c}\text { Relative } \\
\text { change (\%) }\end{array}$} \\
\cline { 3 - 5 } 30 & Direct & 1,183 & 1,325 & 12 \\
\cline { 2 - 5 } & Reverse & 2,145 & 2,855 & 33.1 \\
\hline \multirow{2}{*}{14} & Direct & 846 & 1,038 & 22.7 \\
\cline { 2 - 5 } & Reverse & 1,802 & 1,800 & 0 \\
\hline \multirow{2}{*}{17} & Direct & 1,595 & 1,764 & 10.6 \\
\cline { 2 - 5 } & Reverse & 1,364 & 2,233 & 63.7 \\
\hline \multirow{2}{*}{80} & Direct & 674 & 930 & 38 \\
\cline { 2 - 5 } & Reverse & 1,373 & 1,687 & 22.9 \\
\hline
\end{tabular}


In practice, the creation of a lane for public transport is easily implemented in those sections where the lane is added to the existing traffic lanes during the reconstruction of the highway. In those areas where a bus lane is created by reducing the number of lanes for personal transport, as a rule, there are large traffic congestions for cars. This causes serious social negative effects, therefore, the introduction of public transport lanes in Russian cities is slow. Therefore, in parallel with the development of infrastructure for public transport, it is necessary to develop infrastructure for cycling.

Assessment of changes in passenger traffic on routes with the introduction of paid parking is necessary to assess the carrying capacity and "new" demand for those routes. If the demand for a trip on a particular route has increased significantly, then it is important to determine the number of additional buses or the required passenger capacity of buses for their subsequent replacement. In parallel with the creation of demand for public transport, it is necessary to improve the quality of passenger transportation, including through the development of appropriate infrastructure.

\subsection{The influence of the level of development of infrastructure for public} transport on the structure of urban mobility

One of the important factors affecting the number of trips by public transport is the speed of communication and the time for correspondence. These indicators depend on the level of development of the public transport infrastructure. For a large city that does not have highspeed off-street transport, measures for the development of surface urban transport and its infrastructure are relevant. If in the city there are only bus routes, then it is possible to increase the speed of communication by creating bus lanes on highways. These measures are easily implemented on those sections where the lane is added to the existing traffic lanes during the reconstruction of the highway. In those areas where a bus lane is created by reducing the number of lanes for personal transport, as a rule, large traffic congestions occur.

The hypothesis of the study - with an increase in the length of bus lanes, the demand for trips by public transport increases due to an increased speed of communication and the share of transport movements by other means and on foot decreases.

The modelling results show that with an increase in the length of bus lanes from the existing 18 to $59 \mathrm{~km}$, the number of trips by public transport (Table 2) to the city center increased by 350 trips in the morning. As the number of movements by public transport in

Table 2: Changes in the volume of passenger traffic on certain routes when creating new bus lanes.

\begin{tabular}{|c|c|c|c|}
\hline \multirow{2}{*}{ Route No. } & \multirow{2}{*}{ Traffic direction } & \multicolumn{2}{|c|}{ Passenger traffic on routes, pers. } \\
\hline & & Introduction of paid parking & With bus lanes \\
\hline \multirow{2}{*}{11} & Direct & 1,288 & 1,116 \\
\hline & Reverse & 1,115 & 1,734 \\
\hline \multirow{2}{*}{14} & Direct & 1,038 & 1,088 \\
\hline & Reverse & 1,800 & 1,872 \\
\hline \multirow{2}{*}{17} & Direct & 1,764 & 2,269 \\
\hline & Reverse & 2,233 & 1,503 \\
\hline \multirow{2}{*}{30} & Direct & 1,325 & 1,502 \\
\hline & Reverse & 2,855 & 2,289 \\
\hline & Total in the city & 55,753 & 57,222 \\
\hline
\end{tabular}


Table 3: The number of passengers leaving public transport at stopping points in the central part of the city in the morning.

\begin{tabular}{|l|c|c|}
\hline \multirow{2}{*}{ Bus stop } & \multicolumn{2}{|c|}{$\begin{array}{c}\text { Number of passengers leaving at the stopping point when } \\
\text { creating bus lanes, pers. }\end{array}$} \\
\cline { 2 - 3 } & Actual state & Added bus lanes \\
\hline Tsvetnoy bulvar & 833 & 881 \\
\hline Skver Nemtsova & 1,812 & 1,708 \\
\hline Ploshchad tsentralnaya & 794 & 1,273 \\
\hline Gazprom & 803 & 1,005 \\
\hline Ul. Kholodilnaya & 826 & 1,031 \\
\hline
\end{tabular}

the morning increased, the passenger traffic at stopping points in the city center changed (Table 3).

At the listed stopping points, the number of passengers getting off the buses increased by $17.8 \%$. In parallel with the development of infrastructure for public transport, it is possible to develop infrastructure for cycling.

\subsection{The influence of the level of infrastructure for cyclists on sustainable} urban mobility

Important factors affecting the number of cycling trips are the length of bike lanes, the availability of bike parking lots and bike rentals. When the demand for travel by private transport is limited, the demand for walking, public transport and cycling increases.

The hypothesis of the study - with an increase in the length of bike lanes in a city, there is an increase in the proportion of trips by bicycle transport and a decrease in the proportion of travel by other means and modes of transport.

In this study, in the transport model of the city, $91 \mathrm{~km}$ of bike lanes were created in the paid parking zone and in the direction towards it. The total length of bike lanes in the city model was $128 \mathrm{~km}$. With an increase in the length of bike lanes the number of trips by bicycle to the paid parking zone increased 12 times from 123 to 4,822 trips per day (Fig. 2), and the share of travel by cycle increased to $10.11 \%$ (Fig. 3(a)).

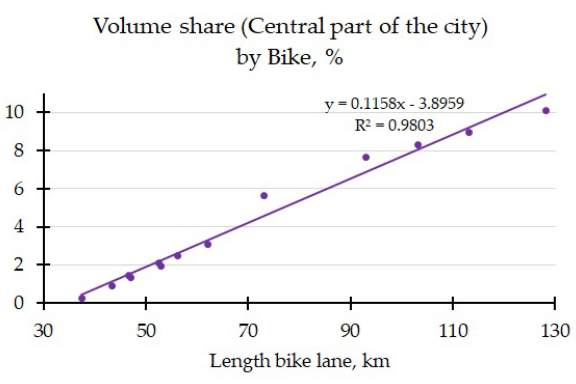

(a)

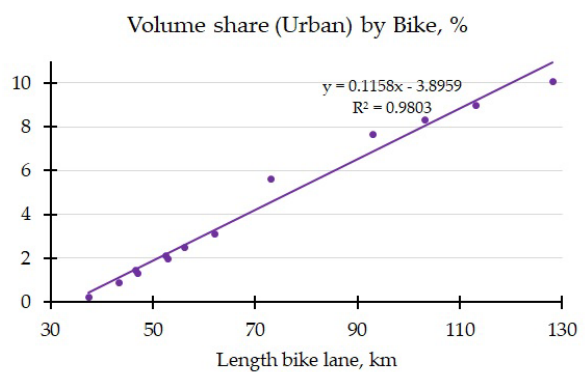

(b)

Figure 3: The influence of the length of bike lanes on the share of cycling trips (paid parking zone in the central part of the city, cost $=120$ rubles per hour). (a) To the central part of the city; and (b) In the city. 


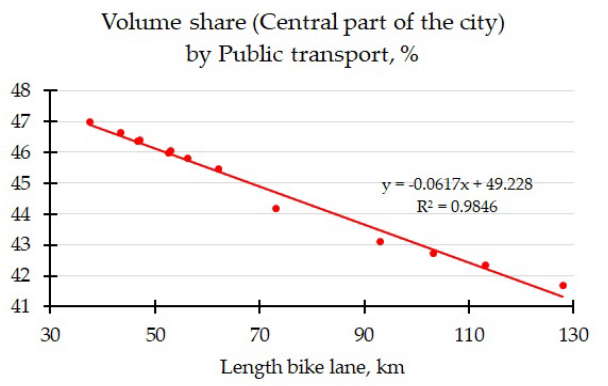

(a)

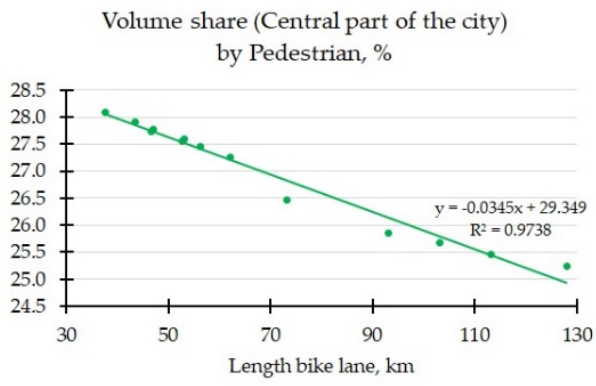

(b)

Figure 4: The influence of the length of bike lanes on the share of cycling trips (paid parking zone in the central part of the city, cost $=120$ rubles per hour). (a) By public transport; and (b) By pedestrian.

The ultimate number of trips in the city as a whole is even higher (an increase to 10,305 trips), but it is increasing with a lower intensity under $7.07 \%$ (Fig. 3(b)). The share of trips by cycle increased due to a decrease in the share of travels by private cars and public transport (Fig. 4).

At the same time, the number of transported passengers on certain routes of public transport and passenger traffic at stopping points are decreasing. Most of all, the share of movements by public transport and on foot decreases. This allows us to conclude that only the development of bicycle infrastructure will not significantly reduce the number of trips by private transport. To achieve sustainable urban mobility, a set of measures is required.

The data obtained were processed using correlation and regression analysis, which allowed the authors to identify statistical characteristics and model parameters. The results of the analysis are presented in Tables 4 and 5. For mathematical models of the demand structure in the central part of the city (eqns (6)-(9)), the coefficient of factors influence and elasticity has a higher value than in models for the city (eqns (10)-(13)) as a whole

$$
\begin{gathered}
\Delta_{c a r}=44.03+0.00015\left(\mathrm{C}_{p p}-\mathrm{C}_{p p 0}\right)^{2}-0.022 L_{\text {buslane }}-0.025 L_{\text {bikelane }}, \\
\Delta_{p t}=39.73-0.0001\left(\mathrm{C}_{p p}-\mathrm{C}_{p p 0}\right)^{2}+0.027 L_{\text {buslane }}-0.033 L_{\text {bikelane }}, \\
\Delta_{p e d}=18.09-0.0000428\left(\mathrm{C}_{p p}-\mathrm{C}_{p p 0}\right)^{2}-0.0036 L_{\text {buslane }}-0.016 L_{\text {bikelane }}, \\
\Delta_{\text {bike }}=-2.13-0.0000019\left(\mathrm{C}_{p p}-\mathrm{C}_{p p 0}\right)^{2}-0.002 L_{\text {buslane }}+0.074 L_{\text {bikelane }} .
\end{gathered}
$$

The correlation between the share of movements in models 6-13 and variables is significant, since the condition $t>t_{p}$ is satisfied. The developed models are adequate, since the condition $F>F_{p}$ is satisfied. Values of a correlation coefficient of more than 0.99 indicate a high tightness of bonds. The high value of the Fisher dispersion ratio, which exceeds the Fisher test, allows authors to conclude that the model is adequate. This suppose also confirms the value of the average approximation error, which is less than $10 \%$

$$
\begin{aligned}
\Delta_{c a r} & =24.19+0.00045\left(\mathrm{C}_{p p}-\mathrm{C}_{p p 0}\right)^{2}-0.026 L_{\text {buslane }}-0.029 L_{\text {bikelane }} \\
\Delta_{p t} & =49.89-0.00032\left(\mathrm{C}_{p p}-\mathrm{C}_{p p 0}\right)^{2}+0.028 L_{\text {buslane }}-0.056 L_{\text {bikelane }}
\end{aligned}
$$




$$
\begin{gathered}
\Delta_{p e d}=29.76-0.00013\left(\mathrm{C}_{p p}-\mathrm{C}_{p p 0}\right)^{2}+0.0014 L_{\text {buslane }}-0.031 L_{\text {bikelane }}, \\
\Delta_{\text {bike }}=-3.81-0.0000053\left(\mathrm{C}_{p p}-\mathrm{C}_{p p 0}\right)^{2}-0.0042 L_{\text {buslane }}+0.116 L_{\text {bikelane }} .
\end{gathered}
$$

Table 4: Statistical characteristics and models 6-9 parameters.

\begin{tabular}{|l|c|c|c|c|}
\hline \multirow{2}{*}{ Statistic characteristic, model parameter } & \multicolumn{4}{|c|}{ Value for models } \\
\cline { 2 - 5 } & 6 & 7 & 8 & 9 \\
\hline Multiple correlation coefficient, $\mathrm{R}$ & 0.99 & 0.99 & 0.98 & 0.99 \\
\hline Calculated value of student criterion $\mathrm{t}$ & 28.34 & 35.13 & 20.57 & 37.15 \\
\hline Table value of student criterion $\mathrm{t}_{\mathrm{p}}$ & \multicolumn{5}{|c|}{2.88} \\
\hline Average approximation error, $\%$ & 0.36 & 0.28 & 0.41 & 6.28 \\
\hline Mean square deviation, $\mathrm{S}_{\mathrm{y}}$ & 1.64 & 1.34 & 0.53 & 2.22 \\
\hline Fisher Dispersion Ratio $\mathrm{F}$ & 50.64 & 79.38 & 26.57 & 89.44 \\
\hline Fisher test $\mathrm{F}_{\mathrm{p}}$ & \multicolumn{5}{|c|}{3.52} \\
\hline
\end{tabular}

Table 5: Statistical characteristics and models 10-13 parameters.

\begin{tabular}{|l|c|c|c|c|}
\hline \multirow{2}{*}{ Statistic characteristic, model parameter } & \multicolumn{4}{|c|}{ Value for models } \\
\cline { 2 - 5 } & 10 & 11 & 12 & 13 \\
\hline Multiple correlation coefficient, $\mathrm{R}$ & 0.99 & 0.99 & 0.976 & 0.99 \\
\hline Calculated value of student criterion $\mathrm{t}$ & 25.7 & 28.8 & 17.93 & 31.17 \\
\hline Table value of student criterion $\mathrm{t}_{\mathrm{p}}$ & \multicolumn{4}{|c|}{2.9} \\
\hline Average approximation error, $\%$ & 1.74 & 0.67 & 0.8 & 8.75 \\
\hline Mean square deviation, $\mathrm{S}_{\mathrm{y}}$ & 4.42 & 3.11 & 1.39 & 3.61 \\
\hline Fisher Dispersion Ratio $\mathrm{F}$ & 44.1 & 55.61 & 21.525 & 65.71 \\
\hline Fisher test $\mathrm{F}_{\mathrm{p}}$ & \multicolumn{5}{|c|}{3.73} \\
\hline
\end{tabular}

\section{DISCUSSION}

The results of the research show that it is very difficult to achieve a significant change in the structure of urban mobility only by stimulating measures. A set of demotivating measures aimed at users of private cars is required. The introduction of parking fees has a significant impact on the structure of urban mobility.

Analysis of the results of the integrated development of transport infrastructure allows us to draw the following conclusions:

- the introduction of parking fees for private vehicles in the city center leads to the maximum share of public transport use by residents of the city;

- the creation of additional lanes for public transport on highways where a small number of routes pass does not have a significant impact on the structure of urban mobility;

- the creation of bike lanes in the city creates a demand for cycling, leading to a decrease in the number of movements by private and public transport, as well as on foot.

Thus, mobility management by regulating the cost of parking and the number of parking spaces gives an initial impetus to achieve a balanced structure of urban mobility corresponding to the level of development of transport infrastructure.

Further changes in the structure of urban mobility can be achieved by increasing the length of lanes for buses and bike lanes, improving the quality of passenger transportation and 
developing a set of incentive measures (development of bike rentals, preferential rates or free travel in public transport, etc.).

\section{CONCLUSIONS}

It is possible to increase the efficiency of traffic management, stability and balance of the transport system with significant transport demand by reducing the number of trips by residents of the city by private transport and using other types of transport.

The theoretical and experimental studies carried out by the authors made it possible to establish the patterns of the influence of the cost of paid parking, the length of the allocated lanes for buses and bike lanes on the structure of the city's urban mobility. The application of the established patterns allows us to formulate recommendations for achieving the optimal structure of urban mobility. This will improve the balance and sustainability of urban transport systems, taking into account their characteristics.

Improving the quality of public transport services through public transport requires additional financial and material costs. However, a decrease in the number of movements by private transport will reduce the costs of developing the road network over time. A decrease in the number of individual transport on highways will improve the technical and operational performance of the rolling stock of public transport and the remaining cars, improve the quality of passenger traffic on highways that do not have dedicated bus lanes.

\section{ACKNOWLEDGEMENT}

The article was prepared as part of the implementation of a state assignment in the field of science for scientific projects carried out by teams of researchers in scientific laboratories of higher educational institutions subordinate to the Russian Ministry of Education and Science on the project: "New patterns and solutions for the functioning of urban transport systems in the paradigm "Transition from owning a personal car to mobility as a service"" (No. 08252020-0014, 2020-2022).

\section{REFERENCES}

[1] Genon, G., Panepinto, D., Viggiano, F., Magaril, E., Abrzhina, L. \& Magaril, R., Sustainability in automotive transport: Russian and Italian experience concerning actual situation and intervention tools. International Journal of Sustainable Development and Planning, 11, pp. 603-615, 2016.

DOI: 10.2495/SDP-V11-N4-603-615.

[2] Reyes-Rubiano, L.S., Sustainable urban freight transport: A simheuristic approach. Proceedings of the Winter Simulation Conference (WSC), Las Vegas, NV, USA, 3-6 Dec., Part F134102, pp. 4620-4621, 2017. DOI: 10.1109/WSC.2017.8248234.

[3] Currie, G. \& De Gruyter, C., Exploring links between the sustainability performance of urban public transport and land use in international cities. Journal of Transport and Land Use, 11, pp. 325-342, 2018. DOI: 10.5198/jtlu.2018.957.

[4] Qian, Y., Ding, L., Wang, W. \& Qiao, G., Green level and sustainability evaluation with bus enterprises. CICTP 2017: Transportation reform and change-equity, inclusiveness, sharing, and innovation. Proceedings of the 17th COTA International Conference of Transportation Professionals, Shanghai, China, 7-9 Jul., pp. 30323041, 2017.

[5] Mohan, D. \& Tiwari, G., Sustainable transport systems: Linkages between environmental issues, public transport, non-motorised. Economic and Political Weekly, 34(25), pp. 1589-1596, 1999. 
[6] Keay, K. \& Simmonds, I., The association of rainfall and other weather variables with road traffic volume in Melbourne, Australia. Accident Analysis and Prevention, 37, pp. 109-124, 2005. DOI: 10.1016/j.aap.2004.07.005.

[7] Koetse, M.J. \& Rietveld, P., The impact of climate change and weather on transport: An overview of empirical findings. Transportation Research Part D, 14, pp. 205-221, 2009. DOI: 10.1016/j.trd.2008.12.004.

[8] Liao, Y., Gil, J., Pereira, R.H.M., Yeh, S. \& Verendel, V., Disparities in travel times between car and transit: Spatiotemporal patterns in cities. Scientific Reports, 10, p. 4056, 2020. DOI: 10.1038/s41598-020-61077-0.

[9] Diao, M., Towards sustainable urban transport in Singapore: Policy instruments and mobility trends. Transport Policy, 81, pp. 320-330, 2019.

DOI: $10.1016 /$ j.tranpol.2018.05.005.

[10] Stroe, C.-C., Panaitescu V.N., Ragazzi, M., Rada, E.C. \& Ionescu, G., Some considerations on the environmental impact of highway traffic. Revista de Chimie, $\mathbf{6 5}$, pp. 152-155, 2014.

[11] Magaril, E., Magaril, R. \& Abrzhina, L., Environmental assessment of the measures increasing the sustainability of motor transport. IOP Conference Series: Earth and Environmental Science, 72(1), 012003, 2017.

[12] Errampalli, M., Chalumuri, R.S. \& Nath, R., Development and evaluation of an integrated transportation system: A case study of Delhi. Proceedings of the Institution of Civil Engineers: Transport, Delhi, India, 21 May, 171, pp. 75-84, 2018.

DOI: $10.1680 /$ jtran.16.00003.

[13] Ganin, A.A., Kitsak, M., Marchese, D., Keisler, J.M., Seager, T. \& Linkov, I., Resilience and efficiency in transportation networks. Science Advances, 3(12), e1701079, 2017. DOI: 10.1126/sciadv.1701079.

[14] Noy, K. \& Givoni, M., Is "smart mobility" sustainable? Examining the views and beliefs of transport's technological entrepreneurs. Sustainability (Switzerland), 10(2), p. 422, 2018. DOI: 10.3390/su10020422.

[15] Parkhurst, G., Influence of bus-based park and ride facilities on users' car traffic. Transport Policy, 7(2), pp. 159-172, 2000. DOI: 10.1016/S0967-070X(00)00006-8.

[16] Pucher, J., Dill, J. \& Handy, S., Infrastructure, programs, and policies to increase bicycling: An international review. Preventive Medicine, 50, S106-S125, 2010. DOI: 10.1016/j.ypmed.2009.07.028.

[17] Van Ommeren, J.N., Wentink, D. \& Rietveld, P., Empirical evidence on cruising for parking. Transportation Research Part A: Policy and Practice, 46, pp. 123-130, 2012. DOI: 10.1016/j.tra.2011.09.011.

[18] Yakimov, M.R., Determination of the optimal number of parking spaces based on the formulation and solution of the optimization problem of the transport demand distribution. Proceedings of the Systems of Signals Generating and Processing in the Field of on Board Communications, Moscow, Russia, 20-21 Mar. p. 8706750, 2019. DOI: 10.1109/SOSG.2019.8706750.

[19] Willson, R.W. \& Shoup, D.C., Parking subsidies and travel choices: Assessing the evidence. Transportation, 17, pp. 141-157, 1990. DOI: 10.1007/BF02125333.

[20] Wilson, R.W., Estimating the travel and parking demand effects of employer-paid parking. Regional Science and Urban Economics, 22(1), pp. 133-145, 1992.

DOI: 10.1016/0166-0462(92)90029-Z.

[21] Thomas, T., Jaarsma, R. \& Tutert, B., Exploring temporal fluctuations of daily cycling demand on Dutch cycle lanes: The influence of weather on cycling. Transportation, 40(1), pp. 1-22, 2013. DOI: 10.1007/s11116-012-9398-5. 
[22] Hamre, A. \& Buehler, R., Commuter mode choice and free car parking, public transportation benefits, showers/lockers, and bike parking at work: Evidence from the Washington, DC Region. Journal Public Transportation 2014, 17, pp. 67-91. DOI: 10.5038/2375-0901.17.2.4.

[23] Rodríguez, D.A., Levine, J., Agrawal, A.W. \& Song J., Can information promote transportation-friendly location decisions? A simulation experiment. Journal of Transport Geography, 19(2), pp. 304-312, 2011.

DOI: $10.1016 /$ j.jtrangeo.2010.04.001.

[24] Gent, Mobiliteit in cijfers. https://stad.gent/nl/mobiliteit-openbare-werken/mobiliteit/ plannen-projecten-subsidies-cijfers-scholenwerking/mobiliteit-cijfers- 0 . Accessed on: 27 May 2020.

[25] HSE, The role of bicycles in changing the city transport system. https://publications.hse.ru/mirror/pubs/share/folder/42r16c0llc/direct/188170750. Accessed on: 27 May 2020.

[26] Esztergár-Kiss, D. \& Kerényi, T., Creation of mobility packages based on the MaaS concept. Travel Behaviour and Society, 21, pp. 307-317, 2020. DOI: $10.1016 /$ j.tbs.2019.05.007.

[27] Karlsson, M.I.C., Sochor, J. \& Strömberg, H., Developing the "service" in mobility as a service: Experiences from a field trial of an innovative travel brokerage. Transportation Research Procedia, 14, pp. 3265-3273, 2016.

[28] Cats, O., Susilo, Y.O. \& Reimal, T., The prospects of fare-free public transport: Evidence from Tallinn. Transportation, 44(5), pp. 1083-1104, 2017.

[29] Veerapanane, S., Taylor, A. \& Kaparias, I., A utility-based model for the evaluation of "Mobility as a Service" applications. 97th Annual Meeting of the Transportation Research Board (TRB), Washington, United States, 7-11 Jan. 2018.

[30] COVID-19 impact on traffic intensity in Pilsen. http://innoconnect.net/covid-19impact-on-traffic-intensity-in-pilsen. Accessed on $10 \mathrm{Jul} .2020$.

[31] Traffic intensity before, during and after intelligent lockdown measures in the Netherlands. www.ams-institute.org/news/traffic-intensity-during-and-afterintelligent-lockdown-measures-netherlands. Accessed on $10 \mathrm{Jul} .2020$.

[32] PTV AG, PTV Visum Manual. http://cgi.ptvgroup.com/vision-help/VISUM_18_ ENG/. Accessed on 23 Jul. 2020. 